\title{
Tridimensional Architecture of the Lamina Propria in the Mouse Soft Palate, with Special Reference to the Connective Tissue Papilla of the Palatal Papilla
}

\author{
By \\ Takashi NAKANO \\ Department of Anatomy, Aichi Medical University, Nagakute, Aichi 480-11, Japan \\ - Received for Publication, May 29, 1991 -
}

Key Words: Connective tissue papilla, Collagen fibril, Palate, SEM, Mouse

\begin{abstract}
Summary: The $\mathrm{NaOH}$ cell-maceration method was applied to the oral surface of the mouse soft palate to demonstrate the tridimensional architecture of the connective tissue papillae (CTP) of the "palatal papillae", and of the openings of the glandular ducts. The CTP of the palatal papillae extremely differed from those of any types of the lingual papillae, and appeared as elliptical wall. Within the elliptical wall, there existed the semicircular or circular internal ridge which surrounded the round depression corresponding to the taste bud. The openings of the glandular ducts were rimmed by the collagen fibers running concentrically. Many fibrils derived from the concentrical fibers, turned to the sagittal direction and then concentrated into the sagittal fibers in the vicinity of the openings.
\end{abstract}

It has been pointed out that the architecture of the epithelial papillae is closely related to that of the connective tissue papillae (CTP) which constitute the framework of the epithelial papillae. The CTP contain blood vessels which nourish the epithelium and nerve fibers that are concerned in sensory functions. Furthermore, the CTP are regarded as adaptive structures which enlarge the epithelialconnective tissue interface in order to archive a broader anchorage for the epithelium (Horstmann, 1954; Karring, 1973; Kobayashi et al., 1987). On the other hand, transplanation experiments have suggested that the features of the epithelium overlying the CTP result from the action of unknown connective tissue inducers (Plagman et al., 1974; Karring et al., 1975). As described above, it must be of interest to study the tridimensional architecture of the CTP.

Recently, direct observation of the CTP by SEM, after removal of the epithelial layer, has been developed. Although some investigators treated the unfixed specimens with sodium bromide (Hull and Warfel, 1986; Suzuki and Takeda, 1987) or EDTA (Klein-Szanto and Schroeder, 1977; Toyoshima and Shimamura, 1982), unfixed specimens are subjected to considerable artifacts. Nagato et al. (1989) applied $\mathrm{HCl}$ treatment at $60^{\circ} \mathrm{C}$, but it resulted in the destruction of the connective tissue architecture. Kobayashi and his co-workers reported long term $\mathrm{HCl}$ treatment at room temperature could success- fully remove the epithelial layer from the connective tissue which was then preserved in their actural (Kobayashi et al., 1987, 1988, 1989a, 1989b, 1989c; Kobayashi and Iwasaki, 1989; Kobayashi, 1990). On the other hand, Ohtani and his co-workers introduced the cell-maceration method with low temperature $\mathrm{NaOH}$ solution, and reported that the method was able to romove cellular elements much more effectively and consistently than any other methods (Ohtani, 1987; Ohtani et al., 1988). However, these investigators have given their attention mainly to the CTP of the lingual papillae.

In this study, the $\mathrm{NaOH}$ cell maceration method (Ohtani, 1987) was applied to the soft palate in order to demonstrate the tridimensional architecture of the CTP of the "palatal papillae." Furthermore, some interesting findings of the collagen fibrillar framework constituting the openings of the glandular ducts will be reported.

\section{Materials and Methods}

20 SMA mice (10 male and 10 female) aged from 6 to 12 months were killed by chloroform anesthesia and their palates were removed. Light microscopy specimens were fixed in Zenker's fluid containing $5 \%$ acetic acid, decalcified in $6 \%$ nitric acid, dehydrated in a graded ethanol series. and embedded in paraffin. They were serially cut into frontal sections 
at a thickness of $5 \mu \mathrm{m}$ and stained with hematoxylin and eosin.

Scanning electron microscopy (SEM) specimens were fixed with $2.5 \%$ glutaraldehyde in phosphate buffer for 2 hours and rinsed in distilled water. For studies of the epithelial surface, the specimens were postfixed with $2 \%$ osmium tetroxide for 2 hours, immersed in $2 \%$ tannic acid for 2 hours, and stained with $2 \%$ osmium tetroxide for 1 hour. They were dehydrated in graded ethanol, replaced with isoamyl acetate and dried at critical point with liquid $\mathrm{CO}_{2}$. For studies of the lamina propria, the specimens were processed by the $\mathrm{NaOH}$ cell-maceration method by Ohtani (1987): they were immersed in a $10 \% \mathrm{NaOH}$ solution for 4 days at room temperature (about $25^{\circ} \mathrm{C}$ ) and rinsed in distilled water until they became transparent. After immersion in $1 \%$ tannic acid for $2-3$ hours, they were rinsed in distilled water for several hours, postfixed with $2 \%$ osmium tetroxide for 1 hour, dehydrated in a graded ethanol, and dried with t-butyl alcohol freeze-drying method (Inoue and Osatake, 1988). All SEM specimens mentioned above were coated with gold and observed under a Jeol-U3 scanning electron microscope.

\section{Results}

\section{Light microscopic findings}

In the oral surface of the soft palate, slightly bulging epithelial papillae (provisionally denominate the "palatal papillae") are observed. They are distributed in the total length of the soft palate from the caudal end of the hard palate to the free margin of the soft palate. Each of the papillae contains one, occasionally two, taste bud. Depending on the plane of sections, the taste bud is observed to rest on the basement membrane and to possess a taste pore at the epithelial surface. The lamina propria underlying the palatal papillae forms the finger-like connective tissue papillae (CTP) projecting into the both sides of the taste bud (Fig. 1).

The excretory ducts of the palatal glands run ventrally short distance to open into the oral surface of the soft palate. The lamina propria projects around the opening of the duct (Fig. 2).

\section{Scanning electron microscopic findings}

After $\mathrm{NaOH}$ treatment, the cellular elements as well as the basement membrane are dissolved to reveal the surface of the lamina propria. In the surface of the lamina propria, there are numerous low folds which run sagittally along the long axis of the soft palate. They are interrupted by the ellipticallyshaped connective tissue papillae (CTP) of the palatal papillae and the openings of the glandular ducts
(Fig. 3).

The CTP of the palatal papillae appear as circumferential elliptical wall with their longer axis directed sagittally (Figs. 3-5). The longer sagittal axis is $70-130 \mu \mathrm{m}$, while the shorter frontal one $40-50 \mu \mathrm{m}$. Within the circumferential elliptical wall, there is semicircular or circular internal ridge surrounding a round depression about $20-40 \mu \mathrm{m}$ in diameter (Fig. 4). In the large CTP, there exist two depressions surrounded circularly by the internal ridges (Fig. 5). At higher magnification, both the elliptical wall and the internal ridge consist of the thick bundles of numerous interwoven collagen fibrils (Fig. 6). The bottom of the depression surrounded by the internal ridge is covered with an extremely delicate meshwork of collagen fibrils, which come off from the inner surface of the CTP and are arranged in two opposing spirals. The delicate fibrillar meshwork is frequently perforated by many fenestrations of various size $(0.6-2.0 \mu \mathrm{m}$ in diameter). The collagen fibrils run circularly along the rims of the fenestrations at their periphery (Fig. 7).

When the lamina propria in the interpapillary area is observed at higher magnifications, the configuration of the collagen fibrils is different according to the region of location. In the central region of the soft palate, the collagen fibrils do not collect into fibers but form a delicate fibrillar meshwork. There are also many switchback fibrils (Fig. 8). In the lateral region of the soft palate, on the contrary, the fibrils show some tendency to concentrate into the thicker fibers which run side by side sagittally or obliquely from rostrolateral side to caudomedial side. In between the fibers, there are many collagen fibrils with frequent branchings and anastomoses, which come from a fiber and fuse into the neighboring fiber. They also frequently reverse their course and then enter the adjacent fibers (Fig. 9).

The openings of the glandular ducts are circular or elliptical in form. The lamina propria surrounding the opening is slightly elevated from the general level to form the crater-like structure (Figs. 3, 10). Higher magnifications reveal that the opening was rimmed by thick collagen fibers running concentrically. Many thin fibrils derive from the concentrical fibers, turn to the sagittal direction and then again concentrate into the sagittal fibers which run parallel along the long axis of the soft palate in the vicinity of the opening (Fig. 11, 12). At the inner edge of the opening, on the other hand, the concentrical fibers change their direction radiately and continue to the fibers descending on the wall of the duct into the depth (Fig. 11). 


\section{Discussion}

\section{Connective tissue papilla of palatal papilla}

It has been reported that the epithelial papillae containing taste buds (provisionally denominated the "palatal papillae" in this study) are observed in the oral surface of the soft palate of primates (Hoffmann, 1875; Yamamoto et al., 1959; Klein and Schroeder, 1979) and rodents (Kaplick, 1953; Ohtomo, 1954; Yoshioka, 1967; Cleaton-Jones, 1971, 1976; Yoshioka and Muto, 1975; Srivastava and Vyas, 1979; Naganuma et al., 1988). Although the connective tissue papillae (CTP) are histologically and physiologically of interest as described in introductory paragraph, those of the palatal papillae have been little studied. One exception is the study by Klein and Schroeder (1979), who reported the finger-like CTP of various height and configuration at light microscopic sections in crab-eating macaque. However, direct observation by SEM is indispensable for the collection of detailed information.

Recently, direct observation of the CTP of the lingual papillae by SEM, after removal of the epithelium, has been developed (Toyoshima and Shimamura, 1982; Hull and Warfel, 1986; Kobayashi et al., 1987, 1988, 1989a, 1989b, 1989c; Suzuki and Takeda, 1987; Nagato et al., 1989; Kobayashi, 1990; Ohshima et al., 1990). The architecture of the CTP is various according to the types of the lingual papillae. Further, it is reported that the CTP of the lingual filiform papillae have substantial morphological variation not only among species but also among differing location on the tongue in the same species (Kobayashi et al., 1987, 1989b, 1989c; Kobayashi and Iwasaki, 1989; Nagato et al., 1989). Generally speaking, however, the CTP of the lingual papillae appear as conical or board-like projections. The CTP of the mouse palatal papillae extremely differed from those of any types of the lingual papillae, i.e., they consisted of the circumferential elliptical wall and the internal ridge. They are, if anything, somewhat similar to the horseshoe-shaped CTP of the filiform papillae in the posterior marginal region of the anterior tongue of Suncus murinus (Kobayashi et al., 1989b). However, the horseshoe-shaped CTP of the Suncus filiform papillae opened rostrally to show a distinct polarity and were devoid of the internal ridge. In this study, the circumferential elliptical wall appears to constitute the framework of the palatal papillae and to provide a stronger connection between the epithelium and the lamina propria by interdigitating with the basal surface of the epithelium. The internal ridge was semicircular or circular, and surrounded partly or completely a round depression. The round depression appears to be the structure dependent upon the taste bud situating on the free surface of the palatal papillae. In other words, the taste bud was maintained by the internal ridge. In a teleologic sense, the taste bud on the free surface of the palatal papillae is subjected to considerable mechanical stress in swallowing and, therefore, it is fit in the depression. In the large CTP, there were two depressions surrounded by the internal ridges, suggesting two taste buds were present.

At the bottom of the depression, there were many fenestrations rimmed circularly by the interlacing collagen fibrils. Suzuki and Takeda (1987) observed in the mouse lingual circumvallate papillae that the basement membrane underlying the taste bud was perforated by many fenestrations, and suggested that the fenestrations were the passageway of nerve fibers across the basement membrane. The fenestrations in this study appear to correspond to the pathway of the nerve fibers, which continue to the fenestrations in the basement membrane and enter the taste bud. However, there is no gainsaying the possibility that the fenestrations function as the passageway for the migrating cells.

\section{Interpapillary area}

The soft palate, of which the bony structure is absent, is involved in the intricate mechanism of swallowing. Therefore, the lamina propria in the soft palate is required not only mechanical resistance but flexibility. Further, Cleaton-Jones (1971, 1972, 1976) suggested in the rat soft palate that the variation of the epithelium was determined by the disposition of the underlying lamina propria. In this study, the collagen fibrils in the central region of the mouse soft palate did not collect into fibers but form a delicate fibrillar meshwork. On the contrary, in the lateral region the fibrils tended to concentrate into the parallel fibers running sagittally or obliquely. It is suggested that the delicate meshwork of the collagen fibrils in the central region is related to extension of the mucosa in swallowing, while the parallel fibers in the lateral region are involved in resisting the excessive stretching force.

\section{Opening of glandular duct}

The configuration of the collagen fibrils constituting the openings of the glandular ducts has not been studied. Although Kobayashi et al. (1988, 1989c) observed the openings of the salivary glands in the cat and mouse tongue treated with $\mathrm{HCl}$ at room temperature, the epithelium lining the ducts could not be removed by this treatment. Ohtani et al. (1988) reported that the primary dermal grooves of the human fingertip skin possessed regularly scattered tunnel-like structures for accomodating the ecrine sweat glands, but they observed only at low magnification. 
Examination in the SEM at high magnifications in this study revealed the structural details of the collagen fibrils constituting the openings of the glandular ducts. Some collagen fibers ran concentrically along the rim of the opening. Thin collagen fibrils derived from such concentrical fibers, turned to the sagittal direction and then again concentrated into the sagittal fibers in the vicinity of the opening. It is suggested that the concentrical fibers provide the openings with a main framework that maintains the mechanical stability and acts as a device for the tight adhesion of the surrounding epithelium. On the other hand, the sagittal fibers in the vicinity of the openings may contribute to the mechanical reinforcement of the main framework, the concentrical fibers.

On the wall of the glandular duct, the collagen fibers were arranged almost parallel from the opening to the depth. It is suggested that the fibers play an important role in resisting the excessive extending forces of the ducts during secretion.

\section{References}

1) Cleaton-Jones, P.: Histological observations in the soft palate of the albino mouse. J. Anat., 110: 39-47, 1971.

2) Cleaton-Jones, P.: Anatomical observations in the soft palate of the albino mouse. Anat. Anz., 131: 419-424, 1972.

3) Cleaton-Jones, P.: An ultrastructural study of keratinized epithelia in the rat soft palate. J. Anat., 122: 23-29, 1976.

4) Hoffmann, A.: Über die Verbretung der Geschmacksknospen beim Menschen. Virchows Arch., 62: 516-529, 1875.

5) Horstmann, E.: Morphologie und Morphogenese des Papillarkörpers der Schleimhäute in der Mundhöhle des Menshen. Z. Zellforsch., 39: 479-514, 1954.

6) Hull, M. T. and Warfel, K. A.: Basal lamina at the epithelialconnective tissue junction in the rat forestomach, esophagus, tongue and palate. Scanning electron microscopic study. Scanning Electron Microscopy, 4: 1395-1401, 1986.

7) Kaplick, M.: Über Vorkommen, Verteilung und histologische Beziehungen der Geschmacksknospen am Munddach einiger Säuger, besondere Nagetiere. Z. Zellforsch., 38: 571-590, 1953.

8) Karring, T.: Mitotic activity in the oral epithelium. J. Periodont. Res. Suppl., 13: 1-47, 1973.

9) Karring, T., Lang, N. P. and Löe, H.: The role of gingival connective tissue in determinating epithelial differentiation. J. Periodont. Res., 10: 1-11, 1975.

10) Klein-Szanto, A. J. P. and Schroeder, H. E.: Architecture and density of the connective tissue papillae of the human oral mucosa. J. Anat., 123: 93-109, 1977.

11) Klein, P. B. and Schroeder, H. E.: Epithelial differentiation and taste buds in the soft palate of the monkey, Macaca irus. Cell Tiss. Res., 196: 181-188, 1979.

12) Kobayashi, K.: Three-dimensional architecture of the connective tissue core of the lingual papillae in the guinea pig. Anat. Embryol., 182: 205-213, 1990.

13) Kobayashi, K. and Iwasaki, S.: Comparative studies on the stereo architecture of the connective tissue papillae in some mammalian tongues; in Motta, Cell and Tissues. A threedimensional approach by modern techniques in microscopy, pp. 303-308, Alan R Liss, New York, 1989.

14) Kobayashi, K., Miyata, K. and Iino, T.: Three-dimensional structures of the connective tissue papillae of the tongue in newborn dogs. Arch. Histol. Jpn. 50: 347-357, 1987.

15) Kobayashi, K., Miyata, K., Iwasaki, S. and Takahashi, K.: Three dimensional structure of the connective tissue papillae of cat lingual papillae (in Japanese with English summary). Jpn. J. Oral Biol., 30: 719-731, 1988.

16) Kobayashi, K., Miyata, K., Asano, T., Kitajima, K., Takahashi, K., Iwasaki, S. and Sasagawa, I.: Three-dimensional structure of the connective tissue core of the lingual papillae in the crab-eating macaque (Macaca fascicularis). (in Japanese with English summary). Shigaku, 77: 13081317, 1989a.

17) Kobayashi, K., Miyata, K., Iwasaki, S. and Takahashi, K.: Three dimensional structure of the connective tissue papillae of the tongue in Suncus murinus (in Japanese with English summary). J. Oral Biol., 31: 363-371, 1989b.

18) Kobayashi, K., Miyata, K., Takahashi, K. and Iwasaki, S.: Three-dimensional architecture of the connective tissue papillae of the mouse tongue as viewed by scanning electron microscopy. Acta Anat. Nippon., 64: 523-538, 1989c.

19) Naganuma, M., Ikeda, M. and Tomita, H.: Changes in soft palate taste buds of rats due to aging and zinc deficiency. Scanning electron microscopic observation. Auris Nasus Larynx, 15: 117-127, 1988.

20) Nagato, T., Nagaki, M., Murakami, M. and Tanioka, H.: Three-dimensional architecture of rat lingual filiform papillae with special reference to the epithelium-connective tissue interface. J. Anat., 165: 177-189, 1989.

21) Ohshima, H., Yoshida, S. and Kobayashi, S.: Blood vascular architecture of the rat lingual papillae with special reference to their relations to the connective tissue papillae and surface struectures. A light and scanning electron microscopic study. Acta Anat., 137: 213-221, 1990.

22) Ohtani, O.: Three-dimensional organization of the connective tissue fibers of the human pancreas. A scanning electron microscopic study of $\mathrm{NaOH}$ treated tissues. Arch. Histol. Jpn., 50: 557-566, 1987.

23) Ohtani, O., Ushiki, T., Taguchi, T. and Kikuta, A.: Collagen fibrillar networks as skeletal frameworks. A demonstration by cell-maceration/scanning electron microscope method. Arch. Histol. Cytol., 51: 249-261, 1988.

24) Ohtomo, N.: Innervation, especially sensory innervation, of soft palate in hedgehog. Arch. Histol. Jpn., 7: 121-126, 1954.

25) Plagman, H. E., Lange, D. E., Bernimoulin, J. P. and Howe, H.: Experimentelle Studie über die Epithelneubildung bei heterotopischen Bindegewebstransplantaten. Deut. zahnärztl. Z., 29: 497-502, 1974.

26) Srivastava, H. C. and Vyas, D. C.: Postnatal development of rat soft palate. J. Anat., 128: 97-105, 1979.

27) Suzuki, Y. and Takeda, M.: Scanning electron microscopic observation of the basement membrane in mouse taste buds. J. Electron Microsc., 36: 98-106, 1987.

28) Toyoshima, K. and Shimamura, A.: Scanning electron microscope study of the epithelium-connective tissue interfaces of the tongue papillae in the rat. Jpn. J. Oral Biol., 24: 1019-1022, 1982

29) Yamamoto, T., Nonoguchi, T., Mogi, M., Kadowaki, S. and Ohta, O.: On the sensory innervation of the soft palate in formosan macaque. Arch. Histol. Jpn., 17: 331-342, 1959.

30) Yoshioka, I.: Histology of the palate of mouse with special reference to distribution of clastic fibers (in Japanese with English abstract). Aichi-Gakuin J. Dent. Sci., 4: 130-136, 1967.

31) Yoshioka, I. and Muto, H.: Scanning electron microscopic observations on the mouse soft palate with special reference 
to postnatal development of gemmal papillae (in Japanese with English abstract). J. Aichi Med. Univ. Ass., 3: 65-68,
1975. 
Plate I
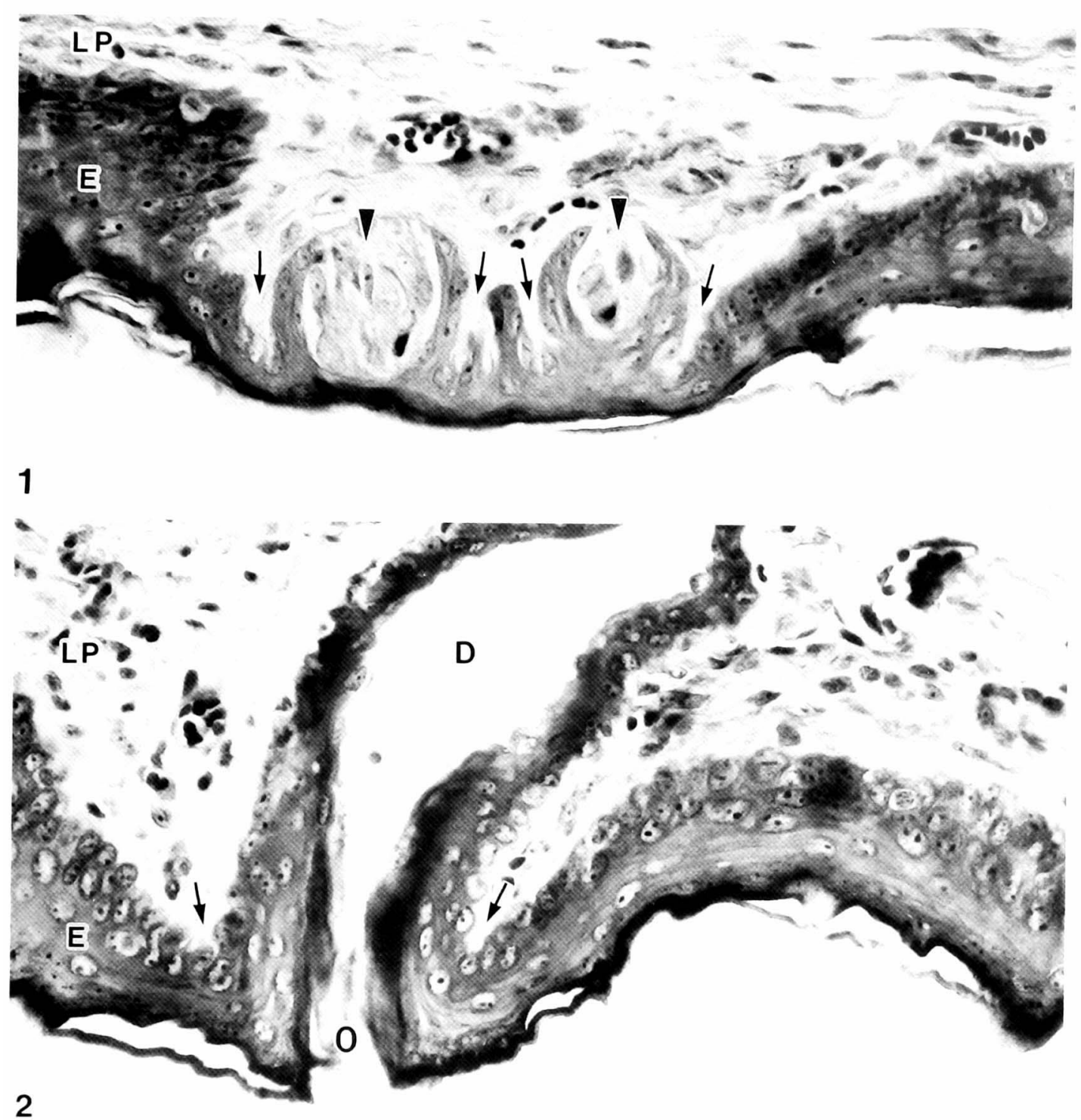

\section{Explanation of Figures}

Plate I

Fig. 1. Light micrograph showing the palatal papilla containing two taste buds (arrowheads). The finger-like connective tissue papillae (arrows) project into the both sides of the taste buds. $\mathrm{E}=$ epithelium. LP $=$ lamina propria. $\times 450$.

Fig. 2. Light micrograph showing the opening $(\mathrm{O})$ of the glandular duct $(\mathrm{D})$. The lamina propria projects around the opening (arrows). $\mathrm{E}=$ epithelium. $\mathrm{LP}=$ lamina propria.$\times 450$. 



Plate II

Fig. 3. Scanning electron micrograph showing the surface of the lamina propria. Numerous low folds (small arrows) are interrupted by the elliptically-shaped connective tissue papillae of the palatal papillae (large arrows) and the openings of the glandular ducts (arrowheads). $\times 100$.

Fig. 4. The connective tissue papilla of the palatal papilla containing one taste bud. It consists of circumferential elliptical wall (arrows) and the internal ridge (arrowheads). The internal ridge surrounds a round depression (d). $\times 500$.

Fig. 5. The connective tissue papilla of the large palatal papilla containing two taste buds. Within the elliptical wall (arrows), there exist two round depressions (d) surrounded by the internal ridges (arrowheads). $\times 500$. 
Plate III


Plate III

Fig. 6. Higher magnification of figure 5 to show the collagen fibrillar architecture of the connective tissue papilla. Both the elliptical wall (arrows) and the internal ridge (arrowheads) consist of the thick bundles of numerous interwoven collagen fibrils. $\times 3,000$.

Fig. 7. Higher magnification of figure 5 to show the bottom of the round depression surrounded by the internal ridge. It is covered with an delicate meshwork of collagen fibrils. Many fenestrations perforating the meshwork are seen (arrowheads). $\times 3,000$.

Fig. 8. Higher magnification of the interpapillary area in the central region of the soft palate. The collagen fibrils form a delicate meshwork. $\times 10,000$.

Fig. 9. Higher magnification of the interpapillary area in the lateral zone of the soft palate. The collagen fibrils concentrate into the thicker fibers (arrows). $\times 10,000$. 

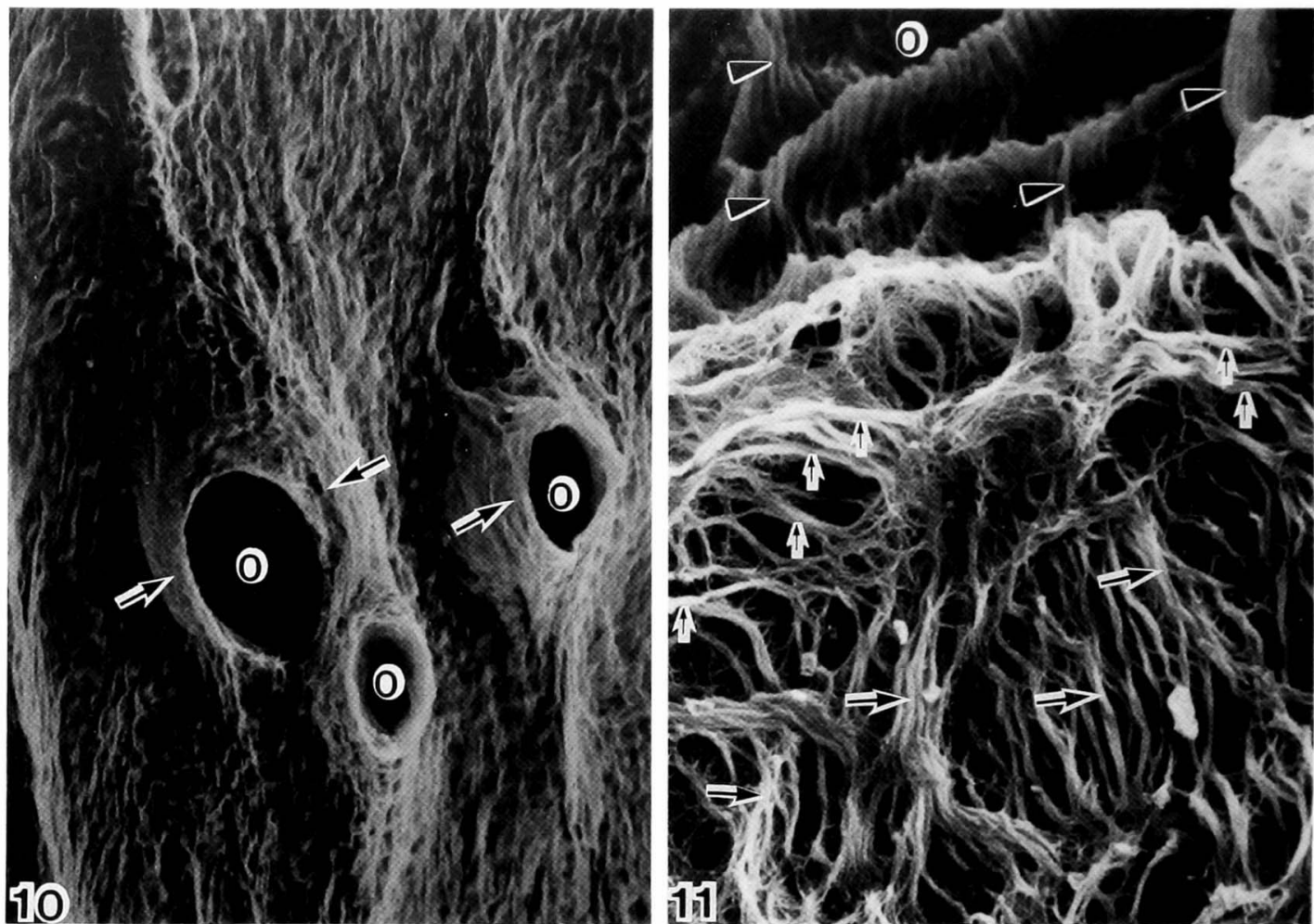

Plate IV



Plate IV

Fig. 10. Scanning electron micrograph showing the openings $(\mathrm{O})$ of the glandular ducts. The lamina propria surrounding the openings is slightly elevated to form the crater-like structure (arrows). $\times 300$.

Fig. 11. Higher magnification to show the collagen fibrils around the opening $(\mathrm{O})$ of the glandular duct. The concentrical fibers (small arrows) rim the opening and then turn their direction to concentratc into the sagittal fibers (large arrows) in the vicinity of the opening. On the wall of the duct, the collagen fibers (arrowheads) descend into the depth. $\times 3,000$.

Fig. 12. Higher magnification of figure 11. Thin fibrils (arrowheads) derive from the concentrical fibers (small arrows), turn to the sagittal direction and concentrate into the sagittal fibers (large arrows) in the vicinity of the opening. $\times 10,000$. 